\title{
Chikungunya and dengue virus infection among febrile children in North-Eastern Tanzania: prospective study
}

Adonira Saro ( $\sim$ adonirasaro@yahoo.com )

Kilimanjaro Christian Medical University College

Debora Kajeguka

Kilimanjaro Christian Medical University College

Kaunara Azizi

Tanzania Food and Nutrition Centre

Steven Mwakalinga

Kilimanjaro Christian Medical University College

\section{Franklin Mosha}

Kilimanjaro Christian Medical University College

\section{Michael Alifrangis}

University of Copenhagen Biotech Research and Innovation Centre

\section{Grace Kinabo}

Kilimanjaro Christian Medical Centre

\section{Reginald Kavishe}

Kilimanjaro Christian Medical University College

\section{Research}

Keywords: Chikungunya, arbovirus infection, febrile illnesses, children, Tanzania

Posted Date: April 27th, 2020

DOI: https://doi.org/10.21203/rs.3.rs-22979/v1

License: (1) (1) This work is licensed under a Creative Commons Attribution 4.0 International License. Read Full License 


\section{Abstract \\ Background}

There are several unknown illnesses including chikungunya and dengue viruses that present with fever in children. Therefore there are many cases that are misdiagnosed. Consequently we performed a study to determine the clinical characteristics of dengue and chikungunya in order to assist clinicians in management.

\section{Methods}

A total of 196 children with history of fever for $\leq 10$ days were enrolled prospectively at Kilimanjaro Christian Medical Centre from September 2015 to May 2016. All cases were screened for chikungunya and dengue viruses by PCR as well as other febrile illnesses such as malaria, bacteria and HIV through other diagnostic method. We performed logistic regression to find association between clinical symptoms and chikungunya infection.

\section{Results}

In our study, $21.9 \%(43 / 196)$ of the cases received laboratory investigations and the diagnoses were as follows; malaria only $(n=1,0.5 \%)$, bacterial infections only $(n=4,2.0 \%)$, HIV/AIDS only $(n=37,18.9 \%)$, as well as malaria, meningitis and urinary tract co-infection $(n=1,0.5 \%)$. Further investigation of all cases revealed that $11.7 \%$ (23) had chikungunya virus while none had dengue virus. For the cases of chikungunya, $78.3 \%$ (18) were below 5 years of age, $65.2 \%$ (15) were females, majority were from Kilimanjaro $95.7 \%$ (22) and Arusha region 4.3\% (1). The clinical features were as follows; nausea/vomit $50.0 \%$ (98), cough $48.5 \%$ (95), convulsion/comma 34.7\%(68), diarrhea $26.0 \%$ (51), joint pain $13.3 \%$ (26), sore throat $7.1 \%(14)$, rashes $4.1 \%(8)$ chills $2.6 \% \varangle 5 \rrbracket$. Nevertheless, there was no statistical significant relationship between chikungunya virus and aforementioned symptoms/signs according to logistic regression.

\section{Conclusion}

This study reveals that chikungunya infection is common cause of febrile illnesses; however it does not have treatment. Therefore, we encourage chikungunya infection to be included in routine investigation as these children are receiving inappropriate treatments such as antibiotics and ant malarial which should be avoided in order to minimize over use of drugs and resource wastage.

\section{Background}


Chikungunya and dengue are arthropod-borne viruses transmitted between humans by the bite of infected female mosquitoes of the genus Aedes, particularly, Ae. Aegypti and Ae. Albopictus(1). At initial stage of infection dengue and chikungunya present with similar febrile illness, such as fever, rashes, joint pain, headache, fatigue, nausea, vomiting and body pain(2). Dengue and chikungunya share similar geographical location and vector (3). Furthermore it is also difficult to distinguish dengue and chikungunya clinically, their clinical symptoms mimics other febrile illnesses such as malaria and typhoid (4). Dengue virus has four serotypes (serotypes $1,-2,-3$, and -4 ), secondary infection with similar serotype confers lifelong immunity but reinfection with other serotype the immune protection becomes weak(5). Chikungunya was first identified in Tanzania in 1952-3(6). Since the discovery of chikungunya, several epidemics in various parts of the world such as west and central African countries have been reported $(7,8)$. However, there are limited occurrence data and less awareness regarding dengue infection in Africa (9). Tanzania is among of the African countries that are endemic for arbovirus vectors $(10,11)$. Unlike dengue, chikungunya is considered to have established as an endemic infection in Tanzania, also it is considered that chikungunya spread from Zanzibar to other parts of the world (12). In 2010, 2012, 2013 and 2014 dengue outbreaks reported in Dar es Salaam, Tanzania (13). Therefore within that period some findings revealed that the prevalence of dengue ranged from $<2 \%$ to $>50 \%$ (14). However dengue outbreak in Tanzania is considered sporadic epidemic most likely imported from elsewhere $(11,15)$. Lack of public awareness on arboviral illnesses and lack of diagnostic capacities in health facilities bring confusion in differentiating causative agent of febrile conditions in Tanzania hospitals. Therefore we aimed to investigate the incidence of dengue and chikungunya infections among febrile children admitted at the Kilimanjaro Christian Medical Centre Hospital in Northern Tanzania.

\section{Material And Methods}

\section{Study design, area and population}

A hospital-based cross sectional study was conducted at pediatric department at Kilimanjaro Christian Medical Centre (KCMC) which is located in Moshi urban district in Kilimanjaro region situated in Northern Tanzania. It serves five regions in Northern part of Tanzania, namely, Arusha, Tanga, Manyara, Singida and Kilimanjaro. It has a bed capacity of 450. This study included children aged 6 months to 13 years, with history of fever 24 hours prior to admission from September 2015 to May 2016. We excluded Children without history of fever and those whose parents refused to consent on behalf.

\section{Data Collection}

Following admission, finger-prick blood samples of approximately $100 \mu \mathrm{l}$ were collected from children and mixed with $900 \mu \mathrm{l}$ of $\mathrm{L} 2$ buffer $(120 \mathrm{~g}$ of guanidine thiocyanate in $100 \mathrm{ml}$ of $0.1 \mathrm{M}$ Tris- $\mathrm{HCl}, \mathrm{pH} 6.4$ ) and stored at $-80^{\circ} \mathrm{C}$ until further use. Informed consent from guardians was used to collect some demographic data such as age, sex, residence and clinical symptoms, provisional diagnosis; previous laboratory test and previous treatment given were recorded. 


\section{RNA Extraction}

Ribonucleic acid (RNA) was extracted from serum samples using the Boom method (16). Briefly, $30 \mu$ of silica was added and vortexed for 5 seconds followed by shaking for $10 \mathrm{~min}$ and centrifuged at 12,000 g for 15 seconds. Supernatant was removed and silica pellets was washed twice with $1 \mathrm{ml}$ of L2 buffer (120 g of guanidine thiocyanate $\{$ GuSCN $\}$ in $100 \mathrm{ml}$ of $0.1 \mathrm{M}$ Tris- $\mathrm{HCl}, \mathrm{pH}$ 6.4). Washed again twice with $1 \mathrm{ml}$ of $70 \%$ ethanol and once with $1 \mathrm{ml}$ of acetone. Silica pellets was dried at $56^{\circ} \mathrm{C}$ for 10 minutes, RNA was eluted from the silica pellets in $50 \mu$ of diethyl pyrocarbonate (DEPEC) treated water and incubated for 10 minutes at $56^{\circ} \mathrm{C}$. Sample was vortexed and centrifuged for 2 minutes at 12,000 g. $35 \mu$ containing purified RNA was transferred to an eppendorf tube and stored at $-20^{\circ} \mathrm{C}$ prior to use. Prior to cDNA synthesis, the extracted RNA were treated with DNase 1 to remove contamination.

\section{cDNA synthesis and Viral DNA detection}

cDNA was synthesized using Superscript ${ }^{\circledR}$ VILO ${ }^{\text {TM }}$ cDNA synthesis kit (Invitrogen, life technologies, USA) according to manufacturer's instructions in a total volume of $20 \mu \mathrm{L}$ containing $2 \mu \mathrm{L}$ of $10 \mathrm{X}$ Superscript ${ }^{\circledR}$ Enzyme Mix, $4 \mu \mathrm{L}$ of $5 X$ VILOTM reaction Mix, $11 \mu \mathrm{L}$ of DEPEC treated water (Ambion, USA) and $3 \mu \mathrm{L}$ of extracted RNA. The reverse transcription programme involved incubation at $25^{\circ} \mathrm{C}$ for 10 minutes, extension at $42{ }^{\circ} \mathrm{C}$ for 60 minutes and inactivation at $85^{\circ} \mathrm{C}$ for 5 minutes. The resulting CDNA was stored in $-20^{\circ} \mathrm{C}$ for further use for dengue and chikungunya polymerase chain reaction (PCR). Dengue PCR was conducted as previously described (17) with respect to dengue only and with minor modifications (14) using TaqMan Gene expression master mix kit (Applied Biosystens, USA). Chikungunya virus investigation was performed using conventional PCR described by Reddy et al., (18). Primers and probes were purchased from Biolegio BV (Nijmegen, the Netherlands).

\section{Data Analysis}

Data were analyzed using IBM SPSS Statistics for Windows, Version 22.0 (IBM Corp, Armonk, NY, USA). Pearson's chi-square ( $\chi 2$ ) and Fisher's exact test (FE) were used to compare categorical data. Association of chikungunya acute infections and symptoms was analyses by logistic regression. A p-value of less than 0.05 was considered statistically significant.

\section{Results}

\section{Clinical features and demographic characteristics}

We were able to recruit 196 children based on inclusion criteria. $112(57.1 \%)$ were males and 84 (42.9\%) were females. The mean age was 3.14 $\pm 2.635 \mathrm{SD}$, median age 3 , ranged from 1 to 12 years. Within 6 month to < 5years, $18(78.3 \%)$ children were diagnosed positive for chikungunya infection and within the age range 5 to13years, $5(21.7 \%)$ children were diagnosed positive for chikungunya infection while none 
were positive for dengue infection by PCR. The most common clinical features observed were: nausea/vomiting $(n=98(50 \%))$, cough $(n=95(48.5 \%))$, convulsion/coma $(n=68(34.7 \%))$, diarrhea $(n=$ $51(26.0 \%))$, joint pain $(n=26(13.3 \%))$, and headache $(n=20(10.2 \%))$. The mean duration of hospital stay was $10 \pm 17.73$ days, Table 1 .

Table 1

Demographic and clinical profile among acute febrile children

\begin{tabular}{|c|c|c|}
\hline \multicolumn{3}{|l|}{ Variable n (\%) } \\
\hline Mean Number of days with fever (SD) & \multicolumn{2}{|l|}{$3.7(2.37)$} \\
\hline Mean duration of hospital stay (SD) & \multicolumn{2}{|l|}{$10(17.73)$} \\
\hline \multirow[t]{2}{*}{ Sex } & Male & $112(57.1)$ \\
\hline & Female & $84(42.9)$ \\
\hline \multirow[t]{9}{*}{ Clinical features at the time of admission $\mathrm{n}(\%)$} & Headache & $20(10.2)$ \\
\hline & Joint Pain & $26(13.3)$ \\
\hline & Cough & $95(48.5)$ \\
\hline & Rashes & $8(4.1)$ \\
\hline & Nausea/Vomit & $98(50.0)$ \\
\hline & Diarrhea & $51(26.0)$ \\
\hline & Chills & $5(2.6)$ \\
\hline & Sore throat & $14(7.1)$ \\
\hline & Convulsion/Coma & $68(34.7)$ \\
\hline
\end{tabular}

\section{Provision Diagnosis}

Among the febrile children, 21 (10.7\%) were provisionally diagnosed as suspected malarial cases, 150 (76.5\%) as bacterial infection, $4(2.0 \%)$ as sickle cell disease, $1(0.5 \%)$ as viral infection and $20(10.2 \%)$ were unknown, meaning that there was no clear provisional diagnosis documented rather than fever. Among those who were provisionally diagnosed as malaria and bacterial infection cases, $3(14.3 \%)$ and $18(12.0 \%)$, respectively were chikungunya positive by PCR (Fischer exact test $=2.83, p=0.5$ ), Table 2 . 
Table 2

Chikungunya infection and provisional diagnosis of febrile children admitted at KCMC pediatric ward $(\mathrm{N}=196)$

\begin{tabular}{|llllll|}
\hline Chikungunya & \multicolumn{4}{l}{ Provisional diagnosis n (\%) } \\
\cline { 2 - 6 } & Unknown & $\infty$ Malaria & Bacteria & Virus & Sickle cell \\
\hline Positive & $1(5.0)$ & $3(14.3)$ & $18(12.0)$ & $0(0.0)$ & $1(25.0)$ \\
\hline Negative & $19(95.0)$ & $18(85.7)$ & $132(88.0)$ & $1(100)$ & $3(75.0)$ \\
\hline Total & $20(10.2)$ & $21(10.7)$ & $150(76.5)$ & $1(0.5)$ & $4(2.0)$ \\
\hline$\infty$ Suspected, Fischer's Exact Test $=2.83, \mathrm{p}=0.5$ & & \\
\hline
\end{tabular}

Therefore among 196 study participants 23(11.7\%) were chikungunya positive by PCR test.

\section{Routine laboratory diagnostic test performed following provisional diagnosis}

Tests performed include blood slide for parasitology, microbial culture and sensitivity together with HIV tests. Laboratory test results revealed $3(1.5 \%)$ of cases was malaria positive, only $1(0.5 \%)$ child with UTI was co-infected with malaria, and 37 (18.9\%) were HIV positive. A total of $23(11.7 \%)$ were chikungunya positive by PCR. Among the 23 chikungunya positive cases, $15(65.2 \%)$ were among those who did not receive conclusive routine clinical laboratory results, while 8 (34.8\%) were HIV positive (Table 3).

Table 3

Chikungunya infection and routine laboratory diagnosis of febrile children admitted at KCMC pediatric ward $(\mathrm{N}=196)$

\begin{tabular}{|c|c|c|c|c|c|c|}
\hline \multirow[t]{2}{*}{ Chikungunya } & \multicolumn{6}{|c|}{ Routine laboratory diagnosis n (\%) } \\
\hline & None & *Malaria & UTI & HIV & **Malaria/UTI & Total \\
\hline Positive & $15(10.2)$ & $0(0.0)$ & $0(0.0)$ & $8(21.6)$ & $0(0.0)$ & $23(11.7)$ \\
\hline Negative & $132(89.8)$ & $3(100)$ & $8(100)$ & $29(78.4)$ & $1(100)$ & $173(88.3)$ \\
\hline Total & $147(75.0)$ & $3(1.5)$ & $8(4.1)$ & $37(18.9)$ & $1(0.5)$ & $196(100)$ \\
\hline
\end{tabular}

*Confirmed by microscopy

${ }^{\star *}$ Co-infection

UTI: Urinary tract infection

Fischer's Exact Test $=4.73, p=0.3$

None = Is the group that did not received any clinical laboratory test at origin, they were provisionally diagnosed only. 


\section{Clinical features among chikungunya positive and negative children}

There were no differences in terms of clinical presentations between Children with acute and those without acute chikungunya infection as shown in Table 4. More analysis shows that there is significant association between HIV positive and acute chikungunya infection $\left(\chi^{2}=4.30, p=0.03\right)$.

Table 4

Frequency of clinical features on admission among chikungunya positive patients of different age

\begin{tabular}{|c|c|c|c|c|}
\hline \multirow[t]{2}{*}{ Symptoms } & \multicolumn{2}{|c|}{ Acute Chikungunya n (\%) } & \multirow[t]{2}{*}{ P-value } & \multirow[t]{2}{*}{ OR $(95 \% \mathrm{Cl})$} \\
\hline & Yes & No & & \\
\hline Headache & $4(17.4)$ & $16(9.2)$ & 0.22 & $0.48(0.14-1.59)$ \\
\hline Joint Pain & $3(13.0)$ & $23(13.3)$ & 1.00 & $1.02(0.28-3.71)$ \\
\hline Cough & 15 (65.2) & $80(46.2)$ & 0.08 & $0.45(0.18-1.13)$ \\
\hline Rashes & $1(4.3)$ & $7(4.0)$ & 0.94 & $0.92(0.10-7.90)$ \\
\hline Nausea/Vomit & $13(56.5)$ & $85(49.1)$ & 0.50 & $0.74(0.30-1.78)$ \\
\hline Diarrhea & $8(34.8)$ & $43(24.9)$ & 0.30 & $0.62(0.24-1.56)$ \\
\hline Chills & $0(0.0)$ & $5(2.9)$ & 0.40 & $0.88(0.83-0.92)$ \\
\hline Sore throat & $1(4.3)$ & $13(7.5)$ & 0.58 & $1.78(0.22-14.34)$ \\
\hline Convulsion/Coma & $6(26.1)$ & $62(35.8)$ & 0.35 & $1.58(0.59-4.22)$ \\
\hline
\end{tabular}

\section{Provision diagnosis and Chikungunya treatment}

Due to the fact that laboratory screening for chikungunya was done retrospectively, chikungunya results were not available for clinical care. Majority of chikungunya positive $20(87.0 \%)$ were treated with antibiotics (ceftriaxone) and none was prescribed with antipyretics or ant-pain (paracetamol). Among patients who were given anti-malarial treatment (artesunate), $52.4 \%$ were given wrong treatment, Table 5 . 
Table 5

Treatment given to provision diagnosed febrile children

\begin{tabular}{|llll|}
\hline Condition & Provisional diagnosis & \multicolumn{2}{l|}{ Appropriate treatment $\mathbf{n}(\%)$} \\
\cline { 3 - 4 } & $\mathbf{n}(\%)$ & Correct & Not correct \\
\hline Unpredictable & $20(9.7)$ & $3(15.0)$ & $16(85.0)$ \\
\hline Malaria infection & $21(10.7)$ & $10(47.6)$ & $11(52.4)$ \\
\hline Bacterial infections & $150(77.0)$ & $120(80.0)$ & $31(20.0)$ \\
\hline Viral Infection & $1(0.5)$ & $0(0.0)$ & $1(100)$ \\
\hline Sickle cell & $4(2.6)$ & $2(50)$ & $2(50)$ \\
\hline & & $\chi 2=43.04, \mathrm{p}$ value $<0.01$ \\
\hline
\end{tabular}

\section{Discussion}

Chikungunya and dengue fever have growing public health impact around the world and both are common infections in the tropical and sub-tropical countries. However, the cause of fever other than malaria and bacterial infection is not often reported. Current estimates suggest that DENV in sub Saharan Africa carries $16 \%$ of the annual world burden (13). The knowledge is still poor regarding arboviral febrile infection, because the clinical guidelines on management of febrile patient in low resource areas focus only on bacterial and malarial infection (19). Moreover there is lack of awareness among clinicians on concurrent of infection due to multiple agents (20). Non specific clinical presentation, limited diagnostic capacities and weak surveillance system made the burden grow big and unnoticed (13). Chikungunya and Dengue infection become misdiagnosed with other febrile infections such as UTI, pneumonia, meningitis and malaria, it is also difficult to distinguish dengue and chikungunya clinically as well(2).

In this study we detected $11.7 \%$ of chikungunya positive cases among hospitalized febrile children. These findings are similar to a pervious hospital study conducted in northern Tanzania, which reported $7.9 \%$ of chikungunya acute infection (21). These results suggest that northern Tanzania is endemic to chikungunya infection. This compel introduction of arboviral testing in the routine laboratory procedures. However absence of dengue infection in our study population and other African settings can possibly be due to lower OSBPL10 expression profile in Africans which is protective against viral hemorrhagic fever and dengue shock syndrome (22). Transmission occurs mostly during epidemics.

Knowledge and awareness on febrile illness etiologies is important for proper disease management. Adittionaly it minimizes drugs over use hence suppressing the emergence of drug resistance, to avoid resource westage because the cost of handling known fever is less than that of unknown fever. In Kenya reports reveals that there is high use rate (33.3\%) of antmalarial treatments for patient having dengue infection(15), suggesting that there is still high under recognition of dengue infection. Morover dengue disease burden in sub saharan African among children is still hidden due to lack of national survaillance 
programs(23). A study conducted in Northern Tanzania among healthcare workers reported low level of knowledge regards to dengue and chikungunya that is why the really burden of arbovirus is not clear (24). Among children, $12.0 \%$ were provisionally diagnosed as having bacterial infection and $14.3 \%$ were provisionally diagnosed as malarial infection, but none of them with viral infection. Our study findings suggest that chikungunya infection in children is under recognized and the burden is not clear. Incorrect diagnosis leaves the patient vulnerable to worsening of the underlying true cause of fever (25). More than $20 \%$ of children who were provisional diagnosed received wrong treatment. Over-treatment has contributed much on the global health challenge, including the emergence of drug resistance, unnecessary adverse drug effects and increased treatment costs (26-28).

None of children were dengue positive by real time PCR assay. To date there is no epidemiological study that shows the prevalence of dengue in northern part of Tanzania although two cases of dengue were detected at KCMC in 2014 (unpublished work). Similar results were obtained by a study (14) which involved patients presenting with malaria-like symptoms in a community cross-sectional study in northeastern Tanzania.

\section{Conclusion}

Chikungunya virus is common among febrile children in northern Tanzania. If symptoms like fever, rashes, vomiting and pain are commonly reported in the context of lack of diagnostic tools, there is strong possibility that chikungunya is unrecognized particularly in endemic settings. This warrants continuous diagnosis of chikungunya among febrile patients in Tanzania at improved healthcare.

\section{Limitations}

The number of confirmed bacterial infections was very low; the reason might be due to inadequate diagnostic tools to confirm wide range of bacterial species. In addition $153(78.1 \%)$ children were not tested in the laboratory this might be because they were treated empirically and recovered in the ward. Most of patients were treated empirically due to lack of advanced diagnostic tools that may quickly yield result for fast treatment, especially for those who presented with severe febrile illnesses.

\section{Abbreviations}

KCMC

Kilimanjaro Christian Medical Centre

$\mathrm{HCl}$

Hydrochloric acid

RNA

Ribonucleic acid

DEPEC

Diethyl pyrocarbonate 
GuSCN

Guanidine thiocynate

PCR

Polymerase chain reaction

UTI

Urinary tract infections

\section{Declarations}

\section{Ethics approval and consent to participate}

Ethical approval for the study was obtained from the Kilimanjaro Christian Medical University College Research Ethical Committee (Cert; No. 880). A written consent form was provided to the HCWs who were consent to participate.

Consent for publication

$\mathrm{N} / \mathrm{A}$

\section{Availability of data and materials}

The data included in this article will be provided upon request from the author.

\section{Competing interests}

The authors declare that they have no competing interests.

\section{Funding}

N/A

\section{Authors' contributions}

ATS: conceived the study, design and performed the study, participated in the field, contributed to interpretation of results and drafted the manuscript. DCK: contributed to the overall study, interpretation of data and critical review of manuscript; KAA: participated in the field and revised the manuscript; SM: contributed to overall study design and critical review of the manuscript, FWM: contributed to overall study design and critical review of the manuscript, MA: contributed to overall study design and critical review of the manuscript, GK: contributed to interpretation of results and critical review of the manuscript, RAK: contributed to overall study design, analysis of data and critical review of the manuscript. All authors read and approved the final manuscript.

\section{Acknowledgements}

The authors would like to thank all participants from pediatric wards at KCMC Hospital. 


\section{References}

1. Reiter P. Aedes albopictus as an epidemic vector of chikungunya virus: another emerging problem? Lancet Infect Dis. 2006;6(8):463-4.

2. Dayaraj C. Current status of dengue and chikungunya in India. WHO South-East Asia J Public Heal. 2014;3(1).

3. Co-infection with Dengue and Chikungunya Viruses

Deeba F, Afreen N, Islam A, Naqvi IH, Broor S, Ahmed A, et al. Co-infection with Dengue and Chikungunya Viruses.

4. Baba M, Logue $\mathrm{CH}$, Oderinde B, Abdulmaleek $\mathrm{H}$, Williams J, Lewis J, et al. Evidence of arbovirus coinfection in suspected febrile malaria and typhoid patients in Nigeria. J Infect Dev Ctries. 2013;7(1):51-9.

5. Peeling RW, Artsob H, Pelegrino JL, Buchy P, Cardosa MJ, Devi S, et al. Evaluation of diagnostic tests: dengue. Nat Rev Microbiol. 2010;8(12):530-8.

6. Lumsden WH. An epidemic of virus disease in Southern Province, Tanganyika Territory, in 1952-53. II. General description and epidemiology. Trans R Soc Trop Med Hyg. 1955;49(1):28-32.

7. Jain M, Rai S, Chakravarti A. Chikungunya: a review. Trop Doct. 2008;38(2):70-2.

8. Pialoux G, Gaüzère BA, Jauréguiberry S, Strobel M. Chikungunya, an epidemic arbovirosis. Vol. 7, Lancet Infectious Diseases. 2007. p. 319-27.

9. Bhatt S, Gething PW, Brady OJ, Messina JP, Farlow AW, Moyes CL, et al. The global distribution and burden of dengue. Nature [Internet]. 2013;496(7446):504-7. Available from:

http://www.pubmedcentral.nih.gov/articlerender.fcgi?

artid $=3651993 \&$ tool $=$ pmcentrez\&rendertype $=$ abstract.

10. Hertz JT, Lyaruu LJ, Ooi EE, Mosha FW, John A, Hertz JT, et al. Distribution of Aedes mosquitoes in the Kilimanjaro Region of northern Tanzania. Pathog Glob Health. 2016;110(3):108-12.

11. Mboera LEG, Mweya CN, Rumisha SF, Tungu PK, Stanley G, Makange MR, et al. The risk of dengue virus transmission in Dar es Salaam, Tanzania during an epidemic period of 2014. PLoS Negl Trop Dis. 2016;10(1):1-15.

12. Halstead SB. Reappearance of chikungunya, formerly called Dengue, in the Americas. Emerg Infect Dis. 2015;21(4):557-61.

13. Boillat-blanco N, Klaassen B, Mbarack Z, Samaka J, Mlaganile T, Masimba J, et al. Dengue fever in Dar es Salaam, Tanzania : clinical features and outcome in populations of black and non-black racial category. 2018;1-10.

14. $10.1186 / \mathrm{s} 12879-016-1511-5$

Kajeguka DC, Kaaya RD, Mwakalinga S, Ndossi R, Ndaro A, Chilongola JO, et al. Prevalence of dengue and chikungunya virus infections in north-eastern Tanzania: a cross sectional study among participants presenting with malaria-like symptoms. BMC Infect Dis [Internet]. 2016;1-9. Available from: http://dx.doi.org/10.1186/s12879-016-1511-5. 
15. Salaam D, Vairo F, Mboera LEG, Nardo P, De, Oriyo NM, Meschi S, et al. Clinical, Virologic, and Epidemiologic Characteristics of Dengue Outbreak, Dar es Salaam, Tanzania, 2014. 2016;22(5):8959.

16. Boom R, Sol CJ, Salimans MM, Jansen CL, Wertheim-van Dillen PM, van der Noordaa J. Rapid and simple method for purification of nucleic acids. J Clin Microbiol. 1990;28:495-503.

17. 10.1016/S1995-7645(12)60055-8

Pongsiri P, Praianantathavorn K, Theamboonlers A, Payungporn S, Poovorawan Y. Multiplex real-time RT-PCR for detecting chikungunya virus and dengue virus. Asian Pac J Trop Med [Internet]. 2012;5(5):342-6. Available from: http://dx.doi.org/10.1016/S1995-7645(12)60055-8.

18. Reddy V, Ravi V, Desai A, Parida M, Powers AM, Johnson BW. Utility of IgM ELISA, TaqMan real-time PCR, reverse transcription PCR, and RT-LAMP assay for the diagnosis of Chikungunya fever. J Med Virol. 2012;84(11):1771-8.

19. $10.4269 /$ ajtmh.2012.11-0393

Hertz JT, Munishi OM, Ooi EE, Howe S, Lim WY, Chow a., et al. Chikungunya and Dengue Fever among Hospitalized Febrile Patients in Northern Tanzania. Am J Trop Med Hyg [Internet]. 2012;86(1):171-7. Available from: http://www.ajtmh.org/cgi/doi/10.4269/ajtmh.2012.11-0393.

20. Srinivasaraghavan R, Narayanan P, Kanimozhi T. Case Report Culture proven Salmonella typhi coinfection in a child with Dengue fever: a case report.

21. Hertz JT, Munishi M, Ooi EE, Howe S, Lim WY, Chow A, et al. Chikungunya and dengue fever among hospitalized febrile patients in northern Tanzania. Am J Trop Med Hyg. 2012 Jan;86(1):171-7.

22. Proesmans S, Katshongo F, Milambu J, Fungula B, Mavoko M, Ahuka-mundeke S, et al. Dengue and Chikungunya among Febrile Outpatients in Kinshasa, Democratic Republic of Congo: a crosssectional study. 2018;1-24.

23. Vu DM, Mutai N, Heath CJ, Vulule JM, Mutuku FM. Unrecognized Dengue Virus Infections in Children, Western Kenya, 2014- 2015. 2017;(January 2018):2014-5.

24. Kajeguka DC, Desrochers RE, Mwangi R, Mgabo MR, Alifrangis M, Kavishe RA, et al. Knowledge and practice regarding dengue and chikungunya: a cross-sectional study among Healthcare workers and community in Northern Tanzania. Trop Med Int Heal. 2017 May;22(5):583-93.

25. Reyburn H, Mbatia R, Drakeley C, Carneiro I, Mwakasungula E, Mwerinde O, et al. Overdiagnosis of malaria in patients with severe febrile illness in Tanzania: a prospective study. BMJ. 2004;329(7476):1212-5.

26. Wongsrichanalai C, Barcus MJ, Muth S, Sutamihardja A, Wernsdorfer WH. A review of malaria diagnostic tools: Microscopy and rapid diagnostic test (RDT). Am J Trop Med Hyg. 2007;77(2):11927.

27. Osei-Kwakye K, Asante KP, Mahama E, Apanga S, Owusu R, Kwara E, et al. The Benefits or Otherwise of Managing Malaria Cases with or without Laboratory Diagnosis: The Experience in a District Hospital in Ghana. PLoS One. 2013;8(3):1-7. 
28. Llor C, Bjerrum L. Antimicrobial resistance: risk associated with antibiotic overuse and initiatives to reduce the problem. Ther Adv Drug Saf. 2014;5(6):229-41. 